\title{
17-alpha hydroxyprogesterone caproate for the prevention of recurrent preterm birth among singleton pregnant women with a prior history of preterm birth: a systematic review and meta-analysis of six randomized controlled trials
}

Saeed Baradwan, MD', Sahar Hassan Abdulghani, MD², Mohammed Abuzaid, MD³, Khalid Khadawardi, MD, Majed Saeed Alshahrani, MD ${ }^{5}$, Abdulrahman Al-Matary, MD ${ }^{6}$, May A. AlRasheed, MD, Najlaa Talat Miski, MD ${ }^{8}$, Aroob Abdulhalim, MD ${ }^{9}$, Yousra Mansour Alturki, MD ${ }^{9}$, Ahmed Abu-Zaid, MD ${ }^{10,11}$

\begin{abstract}
${ }^{1}$ Department of Obstetrics and Gynecology, King Faisal Specialist Hospital and Research Center, Jeddah; ${ }^{2}$ Department of Obstetrics and Gynecology, College of Medicine, King Saud University, King Khalid University Hospital, King Saud University Medical City, Riyadh; ${ }^{3}$ Department of Obstetrics and Gynecology, King Fahad Medical City, Riyadh; ${ }^{4}$ Department of Obstetrics and Gynecology, Faculty of Medicine, Umm Al-Qura University, Makkah; ${ }^{5}$ Department of Obstetrics and Gynecology, Faculty of Medicine, Najran University, Najran; ${ }^{6}$ Department of Neonatology, King Fahad Medical City, Riyadh; ${ }^{7}$ Department of Obstetrics and Gynecology, King Saud Hospital, Unayzah, Qassim; ${ }^{8}$ Department of Obstetrics and Gynecology, Faculty of Medicine at Rabigh, King Abdulaziz University, Rabigh; ${ }^{9}$ Faculty of Medicine, Umm Al-Qura University, Makkah; ${ }^{10}$ Department of Obstetrics and Gynecology, Alfaisal University, Riyadh, Saudi Arabia; ${ }^{11}$ College of Graduate Health Sciences, University of Tennessee Health Science Center, Memphis, TN, USA
\end{abstract}

To perform a systematic review and meta-analysis of all randomized controlled trials (RCTs) that investigated the clinical benefits of 17-alpha hydroxyprogesterone caproate (17OHPC) in the prevention of recurrent preterm birth (PTB) among singleton pregnant women with a previous history of PTB. We searched four major databases up till April 2021 and assessed the risk of bias in the included studies. We meta-analyzed various maternal-neonatal endpoints $(n=18)$ and pooled them as mean difference or risk ratio (RR) with $95 \%$ confidence interval $(\mathrm{Cl})$ using the random-effects model. Six RCTs met the inclusion criteria, comprising 2,573 patients (17OHPC $=1,617$, control=956). RCTs revealed an overall low risk of bias. The rates of PTB $<35$ weeks ( $n=5 \mathrm{RCTs}$; $R R, 0.77 ; 95 \% \mathrm{Cl}, 0.63-0.93 ; P=0.008$ ), PTB $<32$ weeks ( $n=3$ RCTs; RR, $0.68 ; 95 \% \mathrm{Cl}, 0.51-0.91 ; P=0.009)$, neonates with low birth weight $(<2.5 \mathrm{~kg})$ at delivery $(n=3 \mathrm{RCTs} ; \mathrm{RR}$, $0.63 ; 95 \% \mathrm{Cl}, 0.5-0.79 ; P<0.001)$, and neonatal death ( $\mathrm{n}=4 \mathrm{RCTs} ; \mathrm{RR}, 0.41 ; 95 \% \mathrm{Cl}, 0.20-0.84 ; P=0.02$ ) were significantly reduced in the 17OHPC group compared with the control group. Moreover, 170HPC treatment correlated with a significantly decreased rate of retinopathy $(n=2 R C T s ; R R, 0.42 ; 95 \% \mathrm{Cl}, 0.18-0.97 ; P=0.004)$. However, there were no significant differences in the rates of neonatal intensive care unit admission, cesarean delivery, and other pretermrelated complications between both the groups. Among singleton pregnant women with a prior history of PTB, $170 H P C$ may favorably decrease the risks of recurrent PTB and reduce the rate of neonatal death.

Keywords: 17-alpha hydroxyprogesterone caproate; Pregnancy; Preterm birth; Premature birth

Received: 2021.08.09. Revised: 2021.09.20. Accepted: 2021.10.13.

Corresponding author: Ahmed Abu-Zaid, MD

College of Graduate Health Sciences, University of Tennessee Health Science Center, 920 Madison Ave \#807, Memphis, TN 38163, USA

E-mail: aabuzaid@live.com

https://orcid.org/0000-0003-2286-2181

Articles published in Obstet Gynecol Sci are open-access, distributed under the terms of the Creative Commons Attribution Non-Commercial License (http://creativecommons.org/ licenses/by-nc/3.0/) which permits unrestricted non-commercial use, distribution, and reproduction in any medium, provided the original work is properly cited. 


\section{Obstetrics \& Gynecology Science}

Saeed Baradwan, et al. 170HPC for prevention of recurrent PTL

\section{Introduction}

Preterm birth (PTB) is defined as labor starting before 37 completed weeks of gestation since the last menstrual period [1]. It accounts for nearly $11 \%$ of live births worldwide [2]. Additionally, it leads to serious fetal mortality and morbidity, accounting for approximately $35 \%$ of all neonatal deaths [3].

The exact cause of preterm labor remains undetermined. However, some predisposing factors may lead to it. Examples of some maternal factors include congenital anomalies in the genital system, hormonal imbalances, and chronic medical conditions $[4,5]$.

In women with a prior history of spontaneous PTB, all efforts are directed toward preventing the occurrence of recurrent PTB. Unfortunately, this risk seems to be unavoidable. Moreover, the available medical options have their own side effects, in addition to their doubtful efficacy [6-8]. For example, progesterone medications (either natural or synthetic) have been used to prevent the risk of PTB. However, to the best of our knowledge, there is no conclusive evidence to support their regular administration $[7,9]$. Recently, progesterone administration has been shown to decrease the incidence of PTBs in high-risk women [9]. As evidenced by a recent meta-analysis [9], the pooled data suggested the prophylactic use of progesterone administration to be effective in the prevention of PTB. However, these benefits may vary among women at risk, according to the underlying risk factors. Moreover, its efficacy depends on the route of administration and the dose of medication used. Nonetheless, the data were less conclusive regarding the reduction in neonatal complications [9].

Besides, the synthetic progesterone 17-alpha hydroxyprogesterone caproate (17OHPC) has been used for circumventing the recurrence of PTB in high-risk groups. Some studies have shown that $170 \mathrm{HPC}$ is beneficial for decreasing the incidence of PTB [10-14]. In addition, the American College of Obstetricians and Gynecologists (ACOG) supports the use of 17OHPC for women at a risk of PTB [15]. However, recent trials have revealed that $170 \mathrm{HPC}$ is not superior to placebo or no treatment in terms of the risk of PTB before 35 or 37 weeks $[16,17]$.

Overall, the available literature reveals conflicting results about the efficacy of $170 \mathrm{HPC}$ in preventing recurrent PTB. Fernandez-Macias et al. [18] conducted a meta-analysis of four randomized controlled trials (RCTs) comparing 17OHPC to placebo for the prevention of recurrent PTB. They reviewed four databases (not including EMBASE) until August 18, 2018. An updated literature search is warranted to provide contemporary evidence on the topic. We conducted a recent literature search in April 2021 and identified two more high-quality RCTs that were not previously pooled in a metaanalysis $[16,17]$.

Therefore, we conducted a systematic review and metaanalysis of RCTs to holistically assess the efficacy of 17OHPC in the prevention of recurrent PTB among singleton pregnant women with a previous history of PTB, with an aim to provide comprehensive evidence to inform better clinical practice.

\section{Methods}

This systematic review and meta-analysis followed the Preferred Reporting Items for Systematic Reviews and MetaAnalyses (PRISMA) statement [19] and adhered to the guidelines of the Cochrane Handbook for Systematic Reviews of Interventions [20].

\section{Eligibility criteria}

Only RCTs were considered, and they were included if they met the following evidence-based PICO inclusion criteria: (i) population: pregnant women (singleton pregnancy) with a prior history of PTB; (ii) intervention: 170HPC; (iii) comparator: any control intervention including placebo or no treatment; and (iv) outcomes: reliable extraction of any of the primary endpoints (PTB $<37$ weeks, PTB $<35$ weeks, PTB $<32$ weeks, neonates with low birth weight $<2.5 \mathrm{~kg}$ at delivery, and neonatal death) or secondary endpoints (gestational age at delivery in weeks, birth weight in $\mathrm{kg}$, neonatal intensive care unit [NICU] admission, bronchopulmonary dysplasia, respiratory distress syndrome, necrotizing enterocolitis, sepsis, retinopathy, intraventricular hemorrhage grade III-IV, patent ductus arteriosus, maternal corticosteroid administration, cesarean delivery, and tocolytic therapy. We excluded all secondary studies (such as meta-analyses, reviews, and conference abstracts), animal studies, pharmacokinetic studies, and studies with incomplete reported data. Moreover, we excluded patients with other risk factors of PTB such as placenta previa or a prior history of miscarriage. 


\section{Obstetrics \& Gynecology Science}

Vol. 64, No. 6, 2021

\section{Information sources, literature search, and study selection}

We searched PubMed, Scopus, Web of Science, and the Cochrane Central Register of Controlled Trials (CENTRAL) databases until April 2021 for RCTs that met our inclusion criteria. We used the following search strategy: ((preterm labor) OR (preterm birth) OR (premature delivery) OR (premature labor) OR (early delivery) OR (early labor)) AND ((17OHPC) OR (17-a-hydroxyprogesterone caproate) OR (17P) OR (hydroxyprogesterone hexanoate)).

We screened the retrieved articles in three steps. The first step involved importing the results from the electronic databases to a Microsoft Excel sheet software (Microsoft, Redmond, WA, USA) using EndNote software (Clarivate, Philadelphia, PA, USA). The second step included the title and abstract screening of the imported citations. The third step included a full-text screening of the included citations from the second step. Additionally, we manually searched the ref- erences of the included papers for possible missed RCTs. Two investigators independently completed the database search and study selection, and conflicts were resolved by consultation with a third investigator.

\section{Data collection}

We collected three categories of data from each included study. The first category included the baseline characteristics of the included studies and participants (such as the first author, year of publication, country, recruitment period of study participants, study groups, sample size, mean participant age, type of control treatment, and 17OHPC dose). The second category included the primary and secondary endpoints of the meta-analysis. The third category included data on the risk of bias assessment. Six investigators (in groups of two investigators per group) collected the data, and conflicts were resolved by consultation with the first investigator.

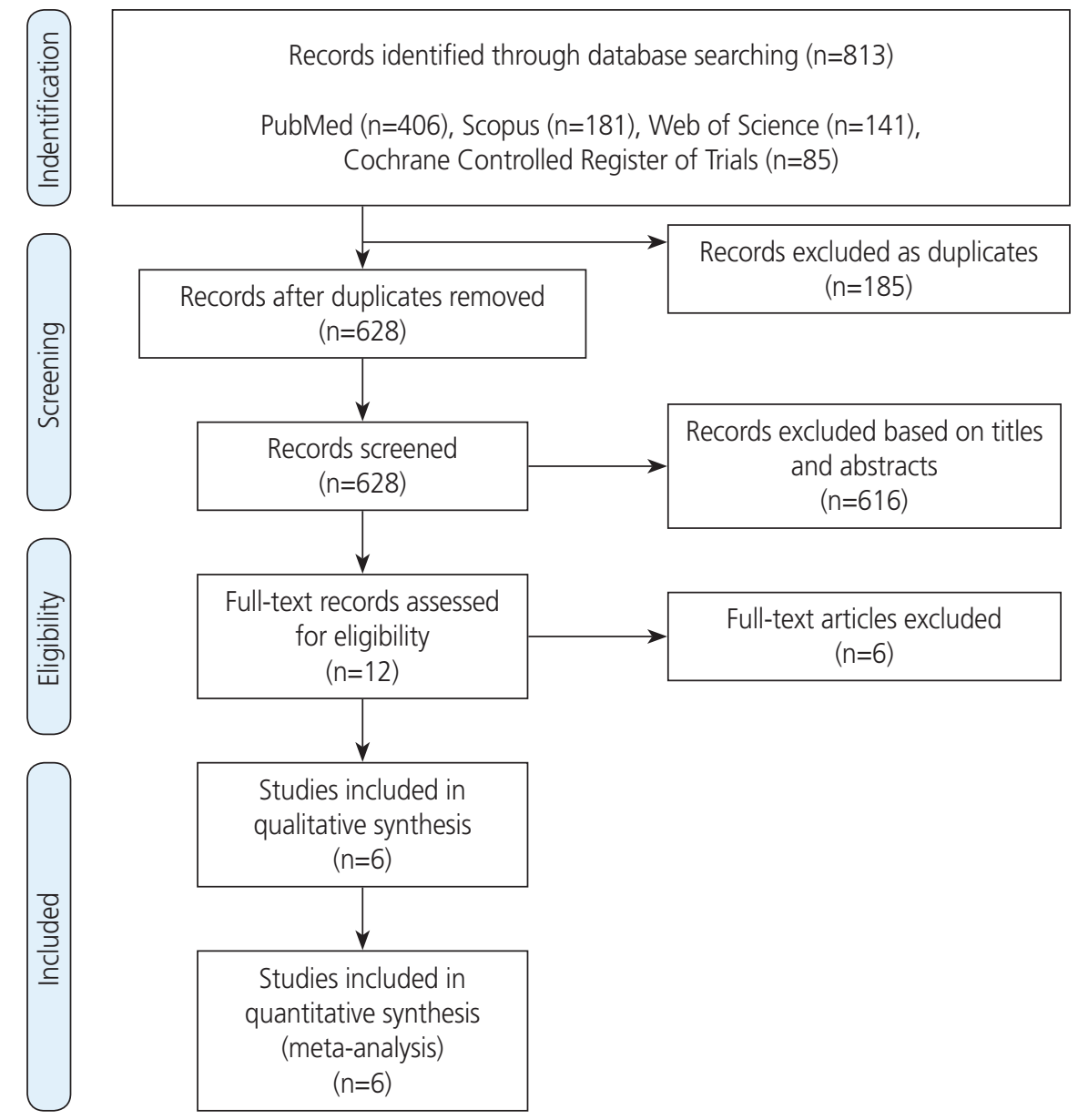

Fig. 1. The preferred reporting items for systematic reviews and meta-analyses flow diagram of the literature search. 


\section{Risk of bias assessment}

We evaluated the risk of bias of the included studies in accordance with the Cochrane risk of bias assessment instrument [21]. This instrument assesses the following domains: (i) random sequence generation, (ii) allocation concealment, (iii) blinding of participants and personnel, (iv) blinding of outcome assessment, (v) incomplete outcome data, (vi) selective outcome reporting, and (vii) other potential sources of bias. Each domain was scored as unclear, low, or high risk. Two investigators independently executed the risk of bias assessment, and inconsistencies were rectified by consensus and consultation with a third investigator.

\section{Analysis}

We performed a meta-analysis of this study using the Review Manager software (Cochrane, London, UK). Our study included continuous and dichotomous outcomes. Continuous outcomes were analyzed using mean difference (MD) and 95\% confidence interval $(\mathrm{Cl})$, whereas dichotomous outcomes were analyzed using risk ratio (RR) and $95 \% \mathrm{Cl}$. In this meta-analysis, the different studies estimated different yet related intervention effects with assumed heterogeneity at the clinical and methodological levels. Therefore, the randomeffects model was used because it is more conservative than the fixed-effects model [20]. To measure the presence of inconsistency among the studies, we used $I^{2}$ and the $P$-value of the chi-square tests [22]. Values of $P<0.1$ or $P^{2}>50 \%$ were significant indicators of the presence of interstudy heterogeneity. We attempted to solve the inconsistency of heterogeneous outcomes using Cochrane's leave-one-out method, if applicable [20]. Subgroup analysis was performed for PTB rates of $<37$ weeks and $<35$ weeks based on cervical length at enrollment. Publication bias was assessed using funnel plots.

\section{Results}

\section{Summary of included RCTs}

Fig. 1 shows the PRISMA flow diagram of the literature search. Overall, six RCTs met the strict inclusion criteria, comprising a total of 2,573 patients (1,617 and 956 patients were assigned to the $17 \mathrm{OHPC}$ and control groups, respectively) $[11-13,16,17,23]$. The baseline characteristics of the included studies are summarized in Table 1.

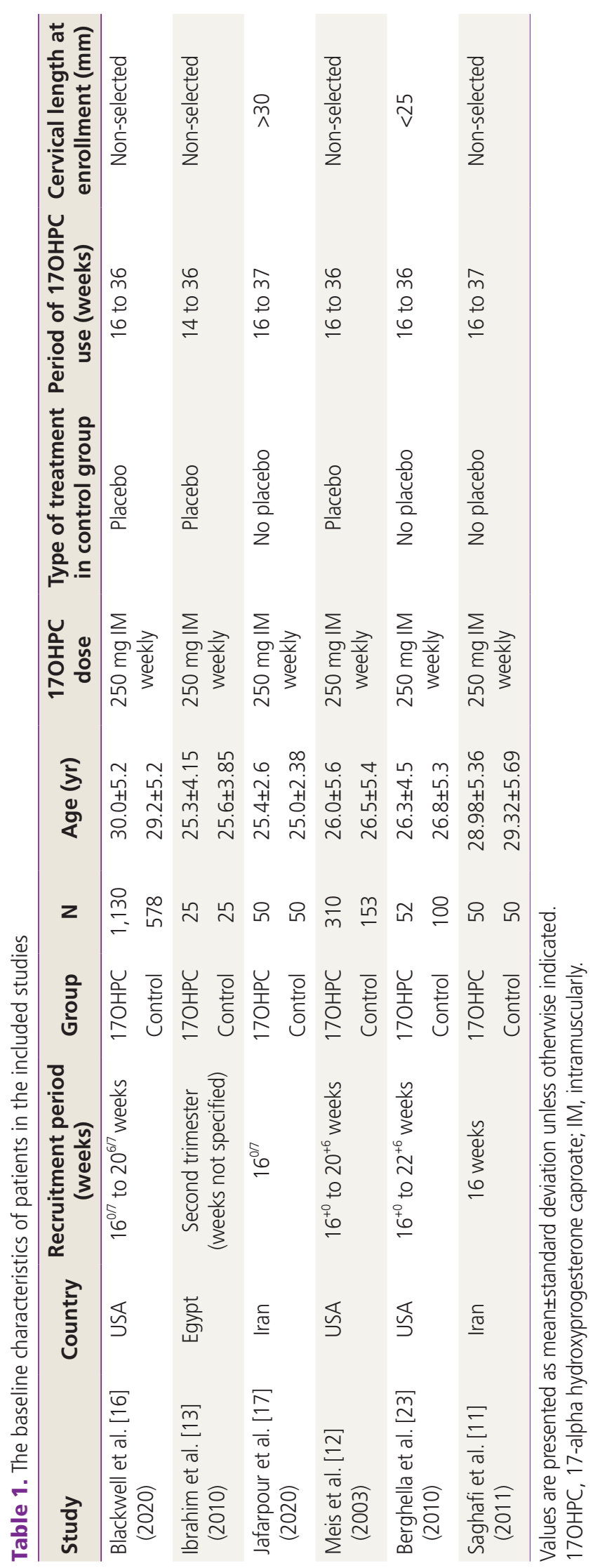




\section{Obstetrics \& Gynecology Science}

Vol. 64, No. 6, 2021

\section{Risk of bias assessment}

The included RCTs yielded an overall low risk of bias. Fig. 2 displays the risk of bias summary and a graph of the included RCTs. Supplementary Table 1 shows the detailed authors' judgment of the risk of bias of the included RCTs.

\section{Meta-analysis of primary endpoints}

1) Rates of PTB $<37$ weeks, $<35$ weeks, and $<32$ weeks The pooled analysis showed no significant difference between groups regarding the rate of PTB $<37$ weeks ( $n=6$ RCTs; RR, 0.79; $95 \% \mathrm{Cl}, 0.62-1.01 ; P=0.06)$. However, the
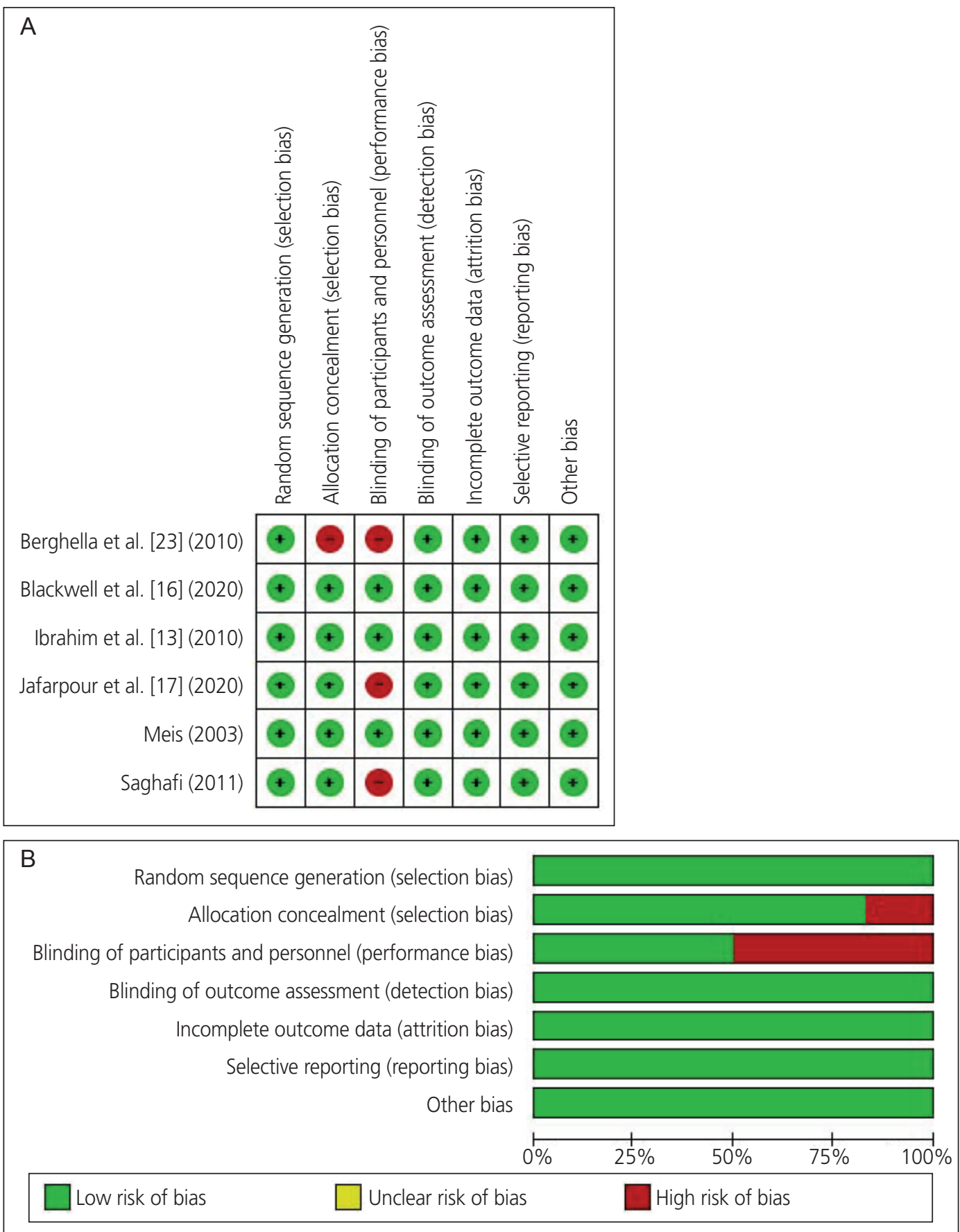

Fig. 2. The risk of bias summary (A) and graph (B) of the included studies. 


\section{Obstetrics \& Gynecology Science}

Saeed Baradwan, et al. 170HPC for prevention of recurrent PTL

rates of PTB $<35$ weeks ( $n=5$ RCTs; RR, $0.77 ; 95 \% \mathrm{Cl}, 0.63$ 0.93; $P=0.008$ ) and PTB $<32$ weeks ( $n=3 R C T s ; R R, 0.68$; $95 \% \mathrm{Cl}, 0.51-0.91 ; P=0.009$ ) were significantly lower in the 17OHPC group than in the control group. The pooled analysis was heterogeneous only for the outcome of PTB $<37$ weeks $\left(P=0.004\right.$ and $\left.I^{2}=71 \%\right)$, and a sensitivity analysis failed to resolve the interstudy heterogeneity. On the other hand, the remaining outcomes were homogeneous ( $P=0.33$ and $I^{2}=13 \%, P=0.46$ and $I^{2}=0 \%$, respectively) (Fig. 3). Subgroup analysis according to the cervical length at enrollment showed that patients with a non-selected cervical length achieved significantly lower rates of PTB $<37$ weeks ( $n=3$ RCTs; RR, 0.64; 95\% Cl, 0.53-0.76; $P<0.001)$ and PTB $<35$ weeks ( $\mathrm{n}=2$ RCTs; RR, 0.63; 95\% Cl, 0.46-0.85; $P=0.002$ ) than those in the other patient categories (Supplementary Fig. 1).

\section{2) Rate of neonates with low birth weight $<2.5 \mathrm{~kg}$ at delivery}

The pooled analysis showed that the rate of neonates with a low birth weight $(<2.5 \mathrm{~kg})$ at delivery did not differ between both the groups ( $n=4$ RCTs; $R R, 0.79 ; 95 \% \mathrm{Cl}, 0.45-1.37$; $P=0.40)$. The pooled analysis was heterogeneous $(P=0.002$, $\left.1^{2}=79 \%\right)$. Between-study heterogeneity was resolved $(c=0.75$ and $I^{2}=0 \%$ ) after the omission of the Saghafi et al. [11] study, and the re-pooled rate of neonates with low birth weight

A

Study or subgroup Berghella et al. [23] (2010) Blackwell et al. [16] (2020) Ibrahim et al. [13] (2010) Jafarpour et al. [17] (2020) Meis et al. [12] (2003) Saghafi et al. [11] (2011)

$\begin{array}{rrr}\text { Events } & \text { Total } & \text { Eve } \\ 31 & 52 & \\ 209 & 1,130 & \\ 8 & 25 \\ 21 & 50 \\ 111 & 306 \\ 16 & 50\end{array}$

Total $(95 \% \mathrm{Cl})$

Total events

1,613

$\begin{array}{lll}613 & 956 \quad 100.0\end{array}$

Control Weight

Risk ratio

Risk ratio

Heterogeneity: Tau $^{2}=0.06 ; \mathrm{chi}^{2}=17.27 ; \mathrm{df}=5(P=0.004) ; I^{2}=71 \%$

Test for overall effect: $Z=1.87(P=0.06)$

(\%) $\mathrm{M}-\mathrm{H}$, random, $95 \% \mathrm{Cl}$

$1.01(0.77,1.33)$

$1.09(0.88,1.36)$

$0.62(0.31,1.22)$

$0.78(0.51,1.18)$

$0.66(0.54,0.81)$

$0.53(0.34,0.85)$

$0.79(0.62,1.01)$

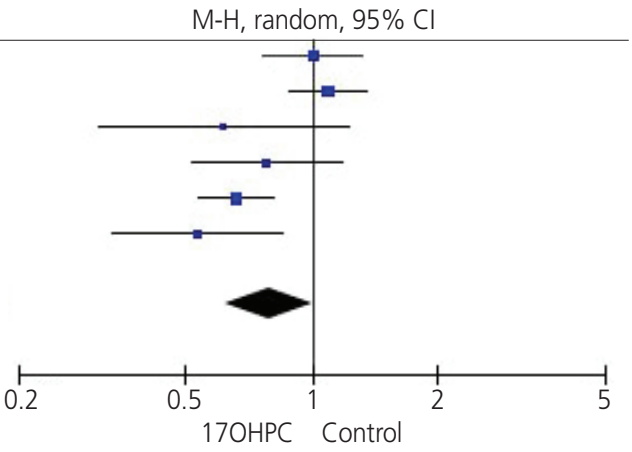

B

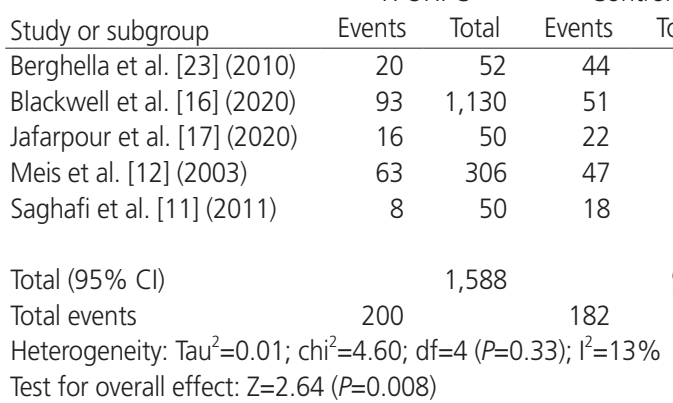

Control Weight Risk ratio (\%) $\mathrm{M}-\mathrm{H}$, random, $95 \% \mathrm{Cl}$

Risk ratio $\mathrm{M}-\mathrm{H}$, random, 95\% Cl $0.87(0.58,1.32)$ $0.93(0.67,1.29)$ $0.73(0.44,1.21)$ $0.67(0.48,0.93)$ $0.44(0.21,0.93)$

$100 \quad 20.2$

29.5

13.6

29.8

$0.44(0.21,0.93)$

$931 \quad 100.0$

$0.77(0.63,0.93)$

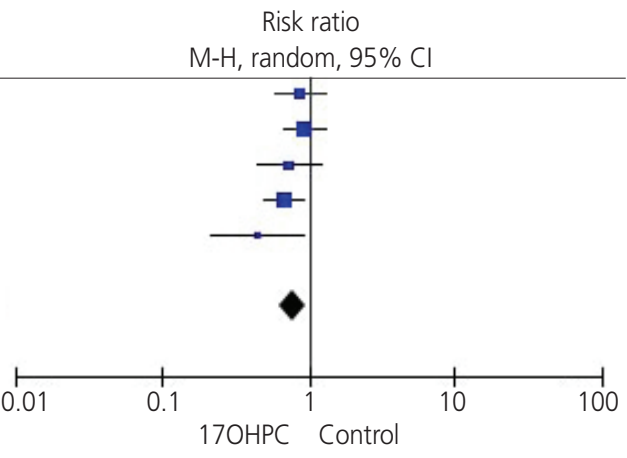

C 17OHPC Control Weight Risk ratio

Study or subgroup Berghella et al. [23] (2010) Blackwell et al. [16] (2020) Meis et al. [12] (2003) Events Tota Weight risk ratio Risk ratio

$\begin{array}{llllll}11 & 52 & 34 & 100 & 24.6 & 0.62(0.34,1.12)\end{array}$

$\begin{array}{llllll}38 & 1,130 & 22 & 578 & 32.4 & 0.88(0.53,1.48)\end{array}$

$\begin{array}{llllll}35 & 306 & 30 & 153 & 43.0 & 0.58\end{array}(0.37,0.91)$

Total $(95 \% \mathrm{Cl})$ Total events 1.488

Heterogeneity: $\operatorname{Tau}^{2}=0.00 ; \mathrm{chi}^{2}=1.54 ; \mathrm{df}=2(P=0.46) ; \mathrm{l}^{2}=0 \%$ Test for overall effect: $Z=2.60(P=0.009)$

$831 \quad 100.0$

$0.68(0.51,0.91)$

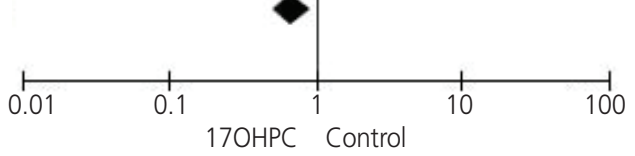

Fig. 3. Meta-analysis of the rates of preterm birth $<37$ weeks (A), $<35$ weeks (B), and $<32$ weeks (C). 170HPC, 17-alpha hydroxyprogesterone caproate; $\mathrm{M}-\mathrm{H}$, Mantel-Haenszel; $\mathrm{Cl}$, confidence interval. 


\section{Obstetrics \& Gynecology Science}

Vol. 64, No. 6, 2021

$(<2.5 \mathrm{~kg})$ at delivery was significantly lower in the 170HPC group compared with the control group ( $n=3 R C T s ; R R, 0.63$; 95\% Cl, 0.5-0.79; $P<0.001$ ) (Fig. 4).

\section{3) Rate of neonatal death}

The pooled analysis showed that the rate of neonatal death was significantly lower in the 170HPC group compared with the control group ( $n=4 R C T s ; R R, 0.41 ; 95 \% \mathrm{Cl}, 0.20-0.84$; $P=0.02)$. The pooled analysis was homogeneous $(P=0.31$ and $\left.\mathrm{I}^{2}=17 \%\right)$ (Fig. 5).

\section{Meta-analysis of secondary endpoints}

1) Mean gestational age at delivery

The pooled analysis showed that the mean gestational age at delivery did not differ between both the groups ( $n=2$ RCTs; MD, 1.63 weeks; $95 \% \mathrm{Cl},-0.49$ to $3.76 ; P=0.13$ ). The pooled analysis was heterogeneous $\left(P<0.001\right.$ and $\left.I^{2}=90 \%\right)$ (Supplementary Fig. 2).

2) Mean birth weight at delivery

The pooled analysis showed that the mean birth weight at delivery was significantly increased in the 17OHPC group

A

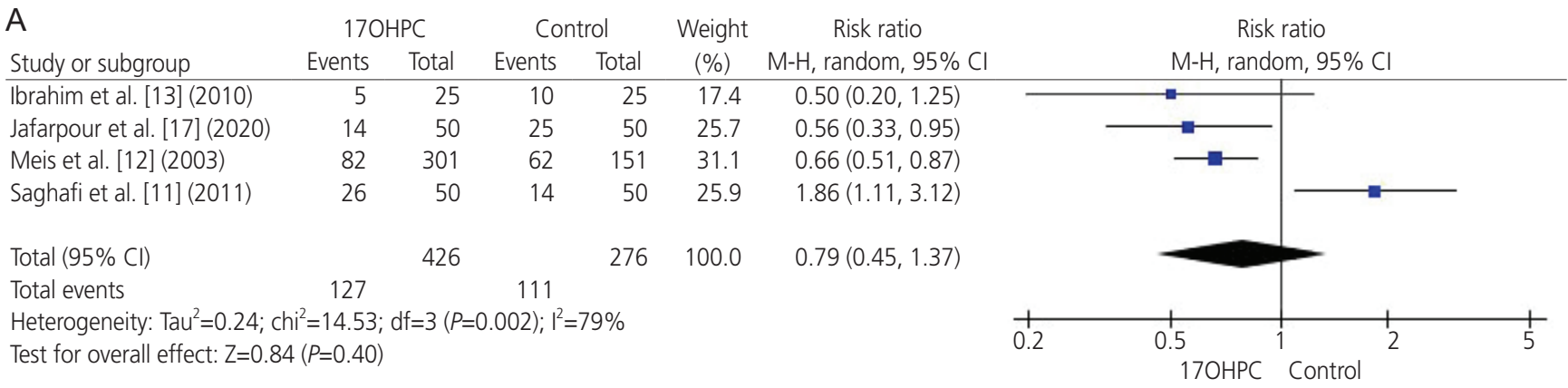

\begin{tabular}{|c|c|c|c|c|c|c|c|c|c|c|}
\hline$B$ & 170 & PC & $\mathrm{Col}$ & & Weight & Risk ratio & & Risk & ratio & \\
\hline Study or subgroup & Events & Total & Events & Total & $(\%)$ & M-H, random, 95\% Cl & & $\mathrm{M}-\mathrm{H}$, rando & $\mathrm{om}, 95 \% \mathrm{Cl}$ & \\
\hline Ibrahim et al. [13] (2010) & 5 & 25 & 10 & 25 & 6.2 & $0.50(0.20,1.25)$ & & & + & \\
\hline Jafarpour et al. [17] (2020) & 14 & 50 & 25 & 50 & 19.2 & $0.56(0.33,0.95)$ & & & & \\
\hline Meis et al. [12] (2003) & 82 & 301 & 62 & 151 & 74.6 & $0.66(0.51,0.87)$ & & & & \\
\hline Total $(95 \% \mathrm{Cl})$ & & 376 & & 226 & 100.0 & $0.63(0.50,0.79)$ & & & & \\
\hline Total events & 101 & & 97 & & & & & & & \\
\hline $\begin{array}{l}\text { Heterogeneity: } \mathrm{Tau}^{2}=0.00 ; \\
\text { Test for overall effect: } Z=3.9\end{array}$ & $\begin{array}{l}=0.58 \\
P<0.00\end{array}$ & $2(P=$ & ); $I^{2}=0$ & & & & 0.2 & $\begin{array}{l}0.5 \\
170 \mathrm{HPC}\end{array}$ & Control & 2 \\
\hline
\end{tabular}

Fig. 4. Meta-analysis of the rates of a low birth weight $(<2.5 \mathrm{~kg})$ at delivery before $(\mathrm{A})$ and after $(\mathrm{B})$ sensitivity analysis using the leaveone-out method. 17OHPC, 17-alpha hydroxyprogesterone caproate; M-H, FULL NAME; Cl, confidence interval.

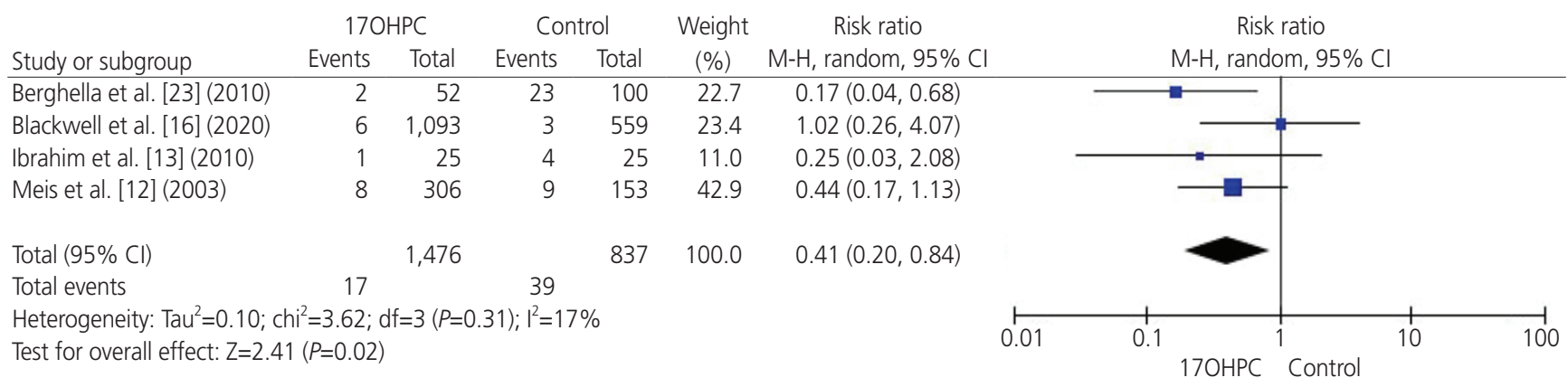

Fig. 5. Meta-analysis of the rate of neonatal death. 170HPC, 17-alpha hydroxyprogesterone caproate; $\mathrm{M}-\mathrm{H}$, Mantel-Haenszel; $\mathrm{Cl}$, confidence interval. 


\section{Obstetrics \& Gynecology Science}

Saeed Baradwan, et al. 170HPC for prevention of recurrent PTL

compared with the control group ( $\mathrm{n}=3 \mathrm{RCTs} ; \mathrm{MD}, 0.12 \mathrm{~kg}$; $95 \% \mathrm{Cl},-0.06$ to $0.30 ; P=0.19)$. The pooled analysis was heterogeneous ( $P=0.02$ and $\left.I^{2}=75 \%\right)$. Interstudy heterogeneity was resolved $\left(P=0.50\right.$ and $\left.P^{2}=0 \%\right)$ after the omission of the study of Blackwell et al. [16], and the re-pooled mean birth weight at delivery was significantly higher in the $170 \mathrm{HPC}$ group than in the control group ( $n=2 R C T s ; M D, 0.21 \mathrm{~kg}$; $95 \% \mathrm{Cl}, 0.07-0.35 ; P=0.004$ ) (Supplementary Fig. 3).

3) Neonatal complications: NICU admission, bronchopulmonary dysplasia, respiratory distress syndrome, necrotizing enterocolitis, sepsis, retinopathy, intraventricular hemorrhage grade III-IV, and patent ductus arteriosus

The pooled analysis showed that the rate of retinopathy $(n=2$ RCTs; RR, 0.42; 95\% Cl, 0.18-0.97; $P=0.004$ ) was significantly reduced in the 17OHPC group compared with the control group. Conversely, the rates of NICU admission ( $n=2$ RCTs; $R R, 0.72 ; 95 \% \mathrm{Cl}, 0.21-2.49 ; P=0.61)$, bronchopulmonary dysplasia ( $n=2$ RCTs; RR, 0.93; 95\% Cl, 0.12-6.98; $P=0.95$ ), respiratory distress syndrome ( $n=2 \mathrm{RCTs} ; \mathrm{RR}, 0.83 ; 95 \% \mathrm{Cl}$, $0.49-1.39 ; P=0.47$ ), sepsis ( $n=2 \mathrm{RCTs} ; \mathrm{RR}, 1.01 ; 95 \% \mathrm{Cl}$, $0.41-2.47 ; P=0.99$ ), retinopathy of necrotizing enterocolitis ( $n=2$ RCTs; RR, 0.22; 95\% Cl, 0.02-1.95; $P=0.17$ ), intraventricular hemorrhage grade III/IV ( $n=2 R C T s ; R R, 1.44 ; 95 \% \mathrm{Cl}$, $0.22-9.64 ; P=0.70$ ), and patent ductus arteriosus ( $n=2 \mathrm{RCTS}$; $R R, 0.46 ; 95 \% C l, 0.20-1.03 ; P=0.06$ ) did not show significant difference between both the groups (Supplementary Fig. 4).

4) Maternal outcomes: rates of cesarean delivery, corticosteroid therapy, and tocolytic therapy

The pooled analysis showed that the rates of cesarean delivery ( $n=2 R C T s ; R R, 1.04 ; 95 \% C l, 0.89-1.21 ; P=0.65)$, corticosteroid therapy ( $n=2 \mathrm{RCTs}$; RR, 0.88; $95 \% \mathrm{Cl}, 0.69-1.11$; $P=0.28$ ), and tocolytic therapy ( $n=2 R C T s ; R R, 1.09 ; 95 \%$ $\mathrm{Cl}, 0.86-1.39 ; P=0.47$ ) did not differ significantly difference between both the groups. All outcomes were homogenous $\left(P>0.1\right.$ and $I^{2}<50 \%$ ) (Supplementary Fig. 5).

\section{Publication bias}

Supplementary Fig. 6 shows the funnel plots for outcomes with overall effect sizes derived from at least three RCTs. Visual (qualitative) inspection of funnel plots revealed asymmetry. However, since the number of included studies was small ( $\mathrm{n}<10 \mathrm{RCTs}$ per outcome), the results of publication bias should be interpreted with caution as they would be unreliable [22]. Therefore, quantitative analysis of publication bias was not performed using the Egger test or the Begg \& Mazumada test.

\section{Discussion}

In this meta-analysis, we evaluated the efficacy of $170 \mathrm{HPC}$ at preventing PTB by pooling data from six RCTs, comprising a total of 2,573 patients $(1,617$ and 956 patients in the $170 H P C$ and control groups, respectively). Overall, compared with the control group, the rates of PTB $(<35$ and $<32$ weeks), neonates with a low birth weight $(<2.5 \mathrm{~kg})$, neonatal death, neonatal necrotizing enterocolitis, and neonatal retinopathy were beneficially reduced in the 170HPC group. Moreover, in contrast to the control group, 17OHPC treatment was correlated with a higher mean birth weight. Nevertheless, there were no significant difference between both the groups with respect to the rates of neonatal (NICU admission, bronchopulmonary dysplasia, respiratory distress, and intraventricular hemorrhage grade III/IV) and maternal (cesarean delivery, corticosteroid therapy, and tocolytic therapy) outcomes.

PTB represents a syndrome rather than a disease that is associated with different etiologies and pathological pathways $[4,5]$. Therefore, it is difficult to identify the factors that may affect the response to medical treatment. This meta-analysis showed that 17OHPC significantly decreased the rates of PTB at $<35$ and $<32$ weeks. Interestingly, only two RCTs $[11,12]$ consistently demonstrated a statistically significant reduction in the rate of PTB. However, in the 2020 17-OHPC to Prevent Recurrent Preterm Birth in Singleton Gestations (PROLONG) study (an international multicenter RCT), Blackwell et al. [16] did not confirm the efficacy of 17OHPC at preventing recurrent PTB in singleton pregnancies. Despite the large sample size of 1,708 patients $(1,130$ and 578 patients in the 17OHPC and placebo groups, respectively), the authors concluded that the sample size was "underpowered," which could have negatively impacted the efficacy endpoint assessment of PTB to reveal statistically significant benefits. Moreover, the authors reported a more frequent rate of stillbirth in the 17OHPC group, although the difference was not statistically significant. Nevertheless, the authors later negated this 


\title{
Obstetrics \& Gynecology Science
}

\author{
Vol. 64, No. 6, 2021
}

relationship between 170HPC and stillbirth after a detailed clinical assessment.

Comparing 170HPC treatment with vaginal progesterone suppositories, Pirjani et al. [24] included asymptomatic patients with short cervix as evidenced by ultrasonography (cervical length $<25 \mathrm{~mm}$ ). They found that the two interventions yielded similar effects with no significant difference in the hazard of PTB (14\% and 10.4\%, respectively). Moreover, they studied the majority of patients for 15 weeks assessing cervical length changes and found no significant difference between both the interventions. Moreover, Choi et al. [25] conducted recent RCT comparing vaginal micronized progesterone to intramuscular 17OHPC and concluded equal efficacy for preventing PTB before 37 weeks of gestation.

In the study by Fernandez-Macias et al. [18], a meta-analysis of the outcome of the rate of low birth weight $(<2.5 \mathrm{~kg})$ at delivery was based on only two RCTs $(n=2)$. However, the meta-analysis in our study was based on a larger number of $R C T s$ ( $n=4$ RCTs). This could explain the intergroup difference in the observed overall effect sizes. The results of Saghafi et al. [11] are very different from those of the other studies included in this meta-analysis $[12,13,16,17,23]$. There are two potential reasons for this inconsistency. First, only the findings of Saghafi et al. [11] showed substantially opposite results compared with the others, and the overall effect size showed a significant interstudy heterogeneity $(P=0.002$, $\left.I^{2}=79 \%\right)$. When we removed the Saghafi et al. [11] using a leave-one-out sensitivity analysis, we resolved the interstudy heterogeneity and reached a homogeneous conclusion (Fig. 4B). Thus, the Saghafi et al. [11] study could have been an outlier. The second reason is that it could be a technical typo by the authors when they reported their findings (Table 1 in their manuscript [11]). This is because the authors showed that the mean newborn weight (g) was significantly increased in the 170HPC group compared with the control group (2,695 g vs. 2,399 g, $P=0.02)$. However, unexpectedly, the rate of low-birth weight neonates $(<2,500 \mathrm{~g})$ was significantly higher in the 170HPC group than in the control group ( $52 \%$ vs. $28 \%, P<0.05$ ). The authors could have mistakenly switched the percentages between the groups, i.e., it should have been $28 \%$ for the 17 OHPC group and $52 \%$ for the control group.

Cervical length is a key determinant of PTB [26]. In our meta-analysis, the subgroup analysis revealed that the rates of PTB $<37$ weeks and PTB $<35$ weeks were significantly lower in patients who had non-selected cervical length at the time of study inclusion and randomization. These data suggest that women with short cervices are unlikely to gain obstetric benefits from 170HPC administration. Nevertheless, because of the small number of studies included in the subgroup analyses, the data should be interpreted with caution, and additional large-sized RCTs are needed to confirm these conclusions.

All the included studies in this meta-analysis started 170HPC as early as 14/16 weeks of gestation until 36/37 weeks of gestation to prevent the risk of PTB. However, the rates of complaints have not been consistently reported. Carter et al. [27] performed a large retrospective cohort study of roughly 3400 patients who received 17OHPC to reduce the risk of PTB. The authors revealed that the early administration of 17OHPC and better 170HPC compliance correlated significantly with decreased frequencies of PTB. Similar findings were reported by Ning et al. [28].

According to the U.S. Food and Drug Administration [29] and a narrative review [30] of two large RCTs [12,16], $170 \mathrm{HPC}$ is well tolerated and has a favorable safety profile. The most frequently reported adverse events of 17OHPC are mild injection-related side effects, such as tenderness, swelling, bruising, itching, and urticaria. Nausea and diarrhea can also occur at very low rates (less than $5 \%$ of patients). Moreover, the rate of severe adverse events culminating in $170 \mathrm{HPC}$ discontinuation is very rare and does not exceed $1.5 \%$. In addition, $170 \mathrm{HPC}$ did not increase the risk of perinatal death. Moreover, maternal-related adverse events of 17OHPC are uncommon and comparable to placebo, including gestational diabetes mellitus, preeclampsia, venous thromboembolism, and cholestasis.

Fernandez-Macias et al. [18] performed a meta-analysis of four RCTs comparing 17OHPC to placebo among singleton pregnant women with a previous history of PTB. The study concluded that 170HPC could potentially decrease the hazards of neonatal death and recurrent $\mathrm{PTB}<37,<35$, and $<28$ weeks. Our meta-analysis is supported by some strengths. First, we included six RCTs that reported a larger sample size and far more detailed maternal and neonatal endpoints $(n=18)$. Most importantly, our meta-analysis incorporated the high-quality PROLONG study [16] and another important study by Jafarpour et al. [17] Thus, our study presents the most contemporary and premium evidence on the effect of $17 \mathrm{OHPC}$ versus placebo/no treatment at preventing recurrent 


\section{Obstetrics \& Gynecology Science}

Saeed Baradwan, et al. 170HPC for prevention of recurrent PTL

PTB among patients with a previous history of PTB. Moreover, the majority of included RCTs yielded a low risk of bias in nearly all assessed domains. However, this meta-analysis is not without its limitations, including the small number of RCTs and their respective small sample sizes. Additional limitations include the heterogeneity of some pooled outcomes as well as the pooling of data from only two RCTs.

\section{Conclusion}

Among singleton pregnant women with a prior history of PTB, this systematic review and meta-analysis suggests that 17OHPC may favorably decrease the risk of recurrent PTB ( $<35$ and $<32$ weeks). Moreover, 17OHPC may advantageously decrease the rates of neonatal death and retinopathy. Considering the efficacy of $170 \mathrm{HPC}$ versus control, future research should include multi-centric trials examining the therapeutic efficacy and safety of $170 \mathrm{HPC}$ versus active comparators or the combination of 17OHPC and an active progestogen.

\section{Conflict of interest}

No potential conflict of interest relevant to this article was reported.

\section{Ethical approval}

This study does not require approval of the Institutional Review Board because no patient data is contained in this article.

\section{Patient consent}

Not applicable.

\section{Funding information}

None.

\section{Supplementary material}

Supplementary Table 1, Supplementary Fig. 1-6 associated with this article can be found online at https://doi. org/10.5468/ogs.21264.

\section{References}

1. WHO: recommended definitions, terminology and format for statistical tables related to the perinatal period and use of a new certificate for cause of perinatal deaths. Modifications recommended by FIGO as amended October 14, 1976. Acta Obstet Gynecol Scand 1977;56:247-53.

2. Blencowe $H$, Cousens $S$, Oestergaard MZ, Chou D, Moller $A B$, Narwal $R$, et al. National, regional, and worldwide estimates of preterm birth rates in the year 2010 with time trends since 1990 for selected countries: a systematic analysis and implications. Lancet 2012;379:2162-72.

3. Liu L, Johnson HL, Cousens S, Perin J, Scott S, Lawn JE, et al. Global, regional, and national causes of child mortality: an updated systematic analysis for 2010 with time trends since 2000. Lancet 2012;379:2151-61.

4. Romero R, Dey SK, Fisher SJ. Preterm labor: one syndrome, many causes. Science 2014;345:760-5.

5. Esplin MS, Manuck TA, Varner MW, Christensen B, Biggio J, Bukowski $R$, et al. Cluster analysis of spontaneous preterm birth phenotypes identifies potential associations among preterm birth mechanisms. Am J Obstet Gynecol 2015;213:429.e1-9.

6. Rubens CE, Sadovsky Y, Muglia L, Gravett MG, Lackritz E, Gravett C. Prevention of preterm birth: Harnessing science to address the global epidemic. Sci Transl Med 2014;6:262sr5.

7. Serra V, Perales A, Meseguer J, Parrilla JJ, Lara C, Bellver $J$, et al. Increased doses of vaginal progesterone for the prevention of preterm birth in twin pregnancies: a randomised controlled double-blind multicentre trial. BJOG 2013;120:50-7.

8. Hermans FJ, Karolinski A, Othenin-Girard V, Bertolino MV, Schuit E, Salgado $P$, et al. Population differences and the effect of vaginal progesterone on preterm birth in women with threatened preterm labor (.). J Matern 


\section{Obstetrics \& Gynecology Science}

Vol. 64, No. 6, 2021

Fetal Neonatal Med 2016;29:3223-8.

9. Tita AT, Rouse DJ. Progesterone for preterm birth prevention: an evolving intervention. Am J Obstet Gynecol 2009;200:219-24.

10. Shaamash AH, Ali MK, Attyia KM. Intramuscular 17a-hydroxyprogesterone caproate to decrease preterm delivery in women with placenta praevia: a randomised controlled trial. J Obstet Gynaecol 2020;40:633-8.

11. Saghafi N, Khadem N, Mohajeri T, Shakeri MT. Efficacy of 17a-hydroxyprogesterone caproate in prevention of preterm delivery. J Obstet Gynaecol Res 2011;37:1342-5.

12. Meis PJ, Klebanoff M, Thom E, Dombrowski MP, Sibai B, Moawad $\mathrm{AH}$, et al. Prevention of recurrent preterm delivery by 17 alpha-hydroxyprogesterone caproate. N Engl J Med 2003;348:2379-85.

13. Ibrahim M, Mohamed Ramy AR, Younis MAF. Progesterone supplementation for prevention of preterm labor: A randomized controlled trial. Middle East Fertil Soc J 2010;15:39-41.

14. Grobman WA, Thom EA, Spong CY, lams JD, Saade GR, Mercer BM, et al. 17 alpha-hydroxyprogesterone caproate to prevent prematurity in nulliparas with cervical length less than $30 \mathrm{~mm}$. Am J Obstet Gynecol 2012;207:390.e1-8.

15. American College of Obstetricians and Gynecologists. ACOG committee opinion. Use of progesterone to reduce preterm birth. Obstet Gynecol 2003;102(5 Pt 1):1115-6.

16. Blackwell SC, Gyamfi-Bannerman C, Biggio JR Jr, Chauhan $\mathrm{SP}$, Hughes BL, Louis JM, et al. 17-OHPC to prevent recurrent preterm birth in singleton gestations (PROLONG study): a multicenter, international, randomized double-blind trial. Am J Perinatol 2020;37:127-36.

17. Jafarpour H, Mousavi SJ, Mirghorbani M, Razavi AR, Atarod Z. Effect of 17 a-hydroxyprogesterone caproate on the prevention of preterm labor: a randomized controlled trial study. J Midwifery Reproductive Health 2020;8:2317-23.

18. Fernandez-Macias R, Martinez-Portilla RJ, Cerrillos L, Figueras $F$, Palacio M. A systematic review and metaanalysis of randomized controlled trials comparing 17-alpha-hydroxyprogesterone caproate versus placebo for the prevention of recurrent preterm birth. Int J Gynaecol Obstet 2019;147:156-64.

19. Moher D, Liberati A, Tetzlaff J, Altman DG; PRISMA
Group. Preferred reporting items for systematic reviews and meta-analyses: the PRISMA statement. PLoS Med 2009;6:e1000097.

20. Higgins JPT, Thomas J, Chandler J, Cumpston M, Li T, Page MJ, et al. Cochrane Handbook for Systematic Reviews of Interventions version 6.2 [Internet]. London (UK): Cochrane; c2021 [cited 2021 May 13]. Available from: www.training.cochrane.org/handbook.

21. Higgins JP, Altman DG, Gøtzsche PC, Jüni P, Moher D, Oxman $A D$, et al. The Cochrane Collaboration's tool for assessing risk of bias in randomised trials. BMJ 2011;343: d5928.

22. Higgins JP, Thompson SG, Deeks JJ, Altman DG. Measuring inconsistency in meta-analyses. BMJ 2003;327:55760.

23. Berghella $V$, Figueroa D, Szychowski JM, Owen J, Hankins $G D$, lams JD, et al. 17-alpha-hydroxyprogesterone caproate for the prevention of preterm birth in women with prior preterm birth and a short cervical length. Am J Obstet Gynecol 2010;202:351.e1-6.

24. Pirjani R, Heidari R, Rahimi-Foroushani A, Bayesh S, Esmailzadeh A. 17-alpha-hydroxyprogesterone caproate versus vaginal progesterone suppository for the prevention of preterm birth in women with a sonographically short cervix: a randomized controlled trial. J Obstet Gynaecol Res 2017;43:57-64.

25. Choi SJ, Kwak DW, Kil K, Kim SC, Kwon JY, Kim YH, et al. Vaginal compared with intramuscular progestogen for preventing preterm birth in high-risk pregnant women (VICTORIA study): a multicentre, open-label randomised trial and meta-analysis. BJOG 2020;127:164654.

26. Thain S, Yeo GSH, Kwek K, Chern B, Tan KH. Spontaneous preterm birth and cervical length in a pregnant Asian population. PLoS One 2020;15:e0230125.

27. Carter EB, Cahill AG, Olsen MA, Macones GA, Tuuli MG, Stout MJ. Practical considerations with 17-Hydroxyprogesterone caproate for preterm birth prevention: does timing of initiation and compliance matter? J Perinatol 2019;39:1182-9.

28. Ning A, Vladutiu CJ, Dotters-Katz SK, Goodnight WH, Manuck TA. Gestational age at initiation of 17-alpha hydroxyprogesterone caproate and recurrent preterm birth. Am J Obstet Gynecol 2017;217:371.e1-371.e7.

29. MAKENA® (hydroxyprogesterone caproate injec- 


\section{Obstetrics \& Gynecology Science}

Saeed Baradwan, et al. 170HPC for prevention of recurrent PTL

tion) for intramuscular or subcutaneous use [Internet]. Silver Spring (MD): U.S. Food and Drug Administration, c2018 [cited 2021 Sep 18]. Available from: https://www.accessdata.fda.gov/drugsatfda_docs/ label/2018/021945s012lbl.pdf.
30. Sibai B, Saade GR, Das AF, Gudeman J. Safety review of hydroxyprogesterone caproate in women with a history of spontaneous preterm birth. J Perinatol 2021;41:71825. 